\title{
LOOKING GOOD
}

The way you

look and feel can

be a great

motivator.

Rosemary Ruston gives some tips.

\section{USEFUL INFORMATION}

\section{Disabled Living \\ Foundation}

380-384 Harrow Road

London W9 $2 \mathrm{HU}$

Tel: 01712896111

\author{
'Keeping fit while caring' \\ Published 1984 \\ Family Welfare \\ Association \\ 501-505 Kingsland \\ Road \\ London E8 4AV \\ ISBN 0900954248
}

L ooking good can make you feel good; feeling good can raise morale; and high morale is a great motivator!

Your clothes, hair and skin, exercise and diet, being interested in what is around you and trying to make time for an interest of your own, are all important.

Much of what is mentioned here will also apply to the person you are caring for, and you can encourage each other.

\section{YOUR CLOTHES}

Know what suits you, including colours and styles, and always try to wear something that pleases you - a favourite colour, tie or piece of jewellery, for example.

The sort of clothes you wear will depend on the person you care for, but when you are working with them have an apron or coverall handy, just in case you need it. Always have something special for special occasions.

Clean clothes feel nice, and should if possible be ironed at least in the places that show.

(See also 'Clothing and footwear', page 132.)

\section{YOUR HAIR}

Hair looks at its best when it is clean and shining. A good cut by a hairdresser makes a great difference. If you prefer long hair but find it impractical, try having a shorter cut and wear a hair piece.

\section{YOUR SKIN}

A clear skin reflects a good diet, with plenty of fresh fruit and vegetables, and cleanliness.
If a daily bath is impossible, try to wash your feet every day - not only will your feet benefit, but a short soak will refresh your whole body.

Massaging the skin keeps it supple. If you like wearing make-up, buy the best you can afford and remove it every night. If you get spots, consider your diet, and if they are persistent, consult your doctor.

A face pack gives you a great lift, as well as a laugh!

\section{EXERCISE}

It is very important that you keep fit while you are caring.

Back strain is a particular risk for carers. (See also 'Lifting and back care: Looking after your back', page 63.)

Other advice on exercise can be found in the book 'Keeping fit while caring', by Christine Darby.

\section{WEIGHT}

Weight affects your health, choice of clothing and energy level. Know what your correct weight should be and try to keep to it.

It is easy to 'snack' when you are busy, but snacks tend to be full of calories. Each mealtime, try to eat at least the main course with some fruit. A microwave can be helpful for reheating.

\section{BE ALIVE}

Having an alert mind and taking an interest in the world around you will keep you from concentrating wholly on what is happening in the house.

Try to have something you can become absorbed in. A short period of relaxation or meditation each day can help enormously. 